\title{
A LONGA E CONTÍNUA JORNADA DA RESISTÊNCIA PETIANA
}

BARATELLI, Amanda Emiliana Santos ${ }^{1}$

RESUMO: O Programa de Educação Tutorial nasceu em 1979, completando, em 2021, 42 anos, no entanto, o PET passou por diversos desafios para sua consolidação, nesse sentido, no artigo em questão o objetiva compreender a jornada de resistência petiana, pautado no pressuposto de que o PET é um importante instrumento educacional para a transformação social e o Mobiliza PET a trincheira para a continuidade da luta petiana. Do ponto de vista metodológico foi realizada revisão bibliográfica nos documentos de Legislação que instituem o programa e de artigos científicos que evidenciam o processo histórico de consolidação do PET. Além disso, foi realizado o levantamento do histórico das ações do Mobiliza PET e suas pautas de reivindicações.

PALAVRAS-CHAVE: Programa de Educação Tutorial; Histórico; Resistência; Luta Petiana; Mobiliza PET.

THE LONG AND CONTINUE JOURNEY FROM THE PETIANO'S RESISTENCE

ABSTRACT: The educational teaching program was born 1979, celebrating the 42th anniversary on 2021. But the educational teaching program have been through a lot of challenges to it's consolidation, so therefore, in this article we look to understand the petiano's resistance journey, on the assumption that the "PET" is an important educational instrument for the social transformation and the "Mobiliza PET" a trench for de petiano's struggle. The methodological point of view, was realized a bibliographic review about the legislative documents that institute the program and scientific articles which highlights the historical process of the "PET's" consolidation. Beyond that, was realized a data of the historical "Mobiliza PET" actions and it's demands.

KEYWORDS: Educational Teaching Program; History; Resistence; Petiano's

\footnotetext{
${ }^{1}$ Egressa do PET Geografia UFMS, mestranda no Programa de Pós Graduação (PPGGeo) da Universidade Federal de Mato Grosso do Sul, campus Três Lagoas (UFMS/CPTL). E-mail: baratelli46@gmail.com
} 
Struggle; Mobiliza PET.

\section{INTRODUÇÃO}

O Programa de Educação Tutorial (PET) possui um estradar de 42 anos, tendo passado por diversos desafios e modificações durante sua trajetória. O processo de consolidação do programa, da forma como é hoje, carrega consigo a dedicação de petianas e petianos que lutaram pela defesa do programa e sua manutenção.

Desta forma, o artigo em questão objetiva compreender a jornada da resistência petiana, pautada em uma análise que considera o PET um importante instrumento de transformação social e, compreender, o Mobiliza PET como uma trincheira para a continuidade da luta petiana em defesa do programa e da educação pública brasileira.

Para consolidar o objetivo proposto foram realizadas análises das Legislações que instituem o programa, tal como a Lei no 11.180, de 23 de setembro de 2005; o Manual de Orientações Básicas (MOB); as Portarias 976/2010 e 343/2013, além de revisão bibliográfica de artigos científicos sobre o estradar do programa.

Nesse sentido, na tentativa de oportunizar o movimento teórico do pensamento 0 artigo foi dividido nos seguintes temas: a) breves considerações sobre o PET e seu estradar; b) o potencial de alcance da luta petiana; c) Mobiliza Pet como trincheira de luta: histórico e reivindicações.

\section{BREVES CONSIDERAÇÕES SOBRE O PET E SEU ESTRADAR}

O Programa de Educação Tutorial (PET) é um programa institucionalizado pelo Ministério da Educação (MEC). Ele é formado por um grupo de estudantes de graduação e por um docente, que cumpre o papel da tutoria. O PET se faz presente em diversas Instituições de Ensino Superior (IES) e seu princípio consiste em manter a indissociabilidade entre ensino, pesquisa e extensão.

O PET possui algumas características ímpares, quando comparado aos demais programas institucionais do MEC. A princípio, pode-se destacar o fato de que ele é regulamentado pela Lei no 11.180 , de 23 de setembro de 2005, em seguida, destaca-se também as proporções, em termos de 
quantidade, atingidas pelo programa, considerando que existem 842 grupos, em 121 Instituições de Ensino Superior.

É evidente que as Legislações e o alcance do programa são fatores a serem enaltecidos, no entanto, as particularidades que realmente chamam a atenção sobre o programa estão relacionadas à sua concepção filosófica. 0 PET possui a particularidade de ser o único programa educacional brasileiro capaz de articular por si só a tríade universitária: pesquisa, ensino e extensão.

A utilização da pesquisa, do ensino e da extensão como princípios educacionais fazem parte da busca pela formação global. Desta forma, o programa tende a distanciar-se da forte tendência em especialização precoce presente no meio acadêmico. Assim:

\begin{abstract}
O Programa de Educação Tutorial constitui-se, portanto, em uma modalidade de investimento acadêmico em cursos de graduação que têm sérios compromissos epistemológicos, pedagógicos, éticos e sociais. Com uma concepção baseada nos moldes de grupos tutoriais de aprendizagem e orientado pelo objetivo de formar globalmente o aluno, o PET não visa apenas proporcionar aos bolsistas e aos alunos do curso uma gama nova e diversificada de conhecimento acadêmico, mas assume a responsabilidade de contribuir para sua melhor qualificação como pessoa humana e como membro da sociedade (BRASIL, 2006, p.5).
\end{abstract}

O programa também possui outras características fundamentais, tal como a educação tutorial. Embora a educação tutorial pareça estar limitada à ação do docente responsável, como tutor e/ou tutora, as relações tutoriais são determinadas pelas atividades cotidianas desenvolvidas no coletivo, em que os próprios discentes exercem a tutoria uns com os outros (AYALA FILHO, 2019).

As relações tutoriais entre discente só são possíveis a partir da execução do trabalho coletivo, que também faz parte de um dos fundamentos do PET. A demanda de atividades a serem cumpridas no planejamento intensifica a necessidade de interação e coletividade entre diversos estudantes, de diferentes períodos do curso e/ou de outros cursos, quando se trata de PETs interdisciplinares.

O PET possui, então, importantes atributos que compõem suas 
características e filosofia, nesse sentido, é importante compreender que a concepção em questão foi construída a partir de desafios enfrentados a 42 anos, idade que o Programa completará em 2021.

O início do PET foi em 1979, idealizado pelo professor Ivan Leite Magalhães e criado pelas CAPES (Coordenação de Aperfeiçoamento de Pessoal de Nível Superior), representada pelo Prof. Dr. Cláudio de Moura Castro. O programa seguia o formato de Programa Especial de Treinamento (PET) e tinha como objetivo central selecionar um grupo seleto de estudantes bolsistas para realizarem atividades de ensino, pesquisa e extensão. A busca pela diferenciação desses estudantes dos demais foi baseada no incentivo ao ingresso na pós-graduação. (MELO FILHO, 2019).

O programa passou por intensos desafios para sua manutenção, todavia, uma das lutas mais importantes travadas pelo PET foi no governo Fernando Henrique Cardoso (FHC), cuja essência pautava-se no discurso neoliberal, que objetivara a diminuição de políticas educacionais. Neste sentido, o governo em questão pretendeu fechar o programa e, em março de 1999, foi emitido pela CAPES o ofício circular 030/99, determinando o fim das atividades do programa em todas as Instituições de Ensino Superior (MELO FILHO, 2019).

Neste período o programa já contava com 317 grupos, em 59 Instituições de Ensino Superior. Emergiu, então, uma sólida identidade petiana, ainda desconhecida, mas que se pautava na resistência. A luta contra o fechamento do programa foi travada durante meses e os petianos tutores e discentes ocuparam diversos espaços, como audiências na Câmara dos Deputados e no Senado, a utilização da internet como espaço de luta e o apoio de instituições, tal como SBPC, ANDES, UNE, ANDIFES, ABRUEM, ABRUC, FORGRAD e ANPG. A visibilidade das formas de resistência fez com que governo recuasse na decisão de fechar o programa. Em novembro de 1999 o ofício circular 13.300/MEC/SESu, manteve o PET e o transferiu para Secretaria de Ensino Superior (SESu), tirando-o da CAPES (MELO FILHO, 2019).

Apesar do anúncio de recuo ao fechamento, o governo FHC manteve seu objetivo e passou a coordenar pesquisas e avaliações 
tendenciosas para medir a produtividade e importância do programa. A surpresa foi que nenhuma dessas avaliações serviriam como argumento para o fechamento, uma vez que os grupos PETs, no geral, desempenhavam importante produtividade e se consolidavam como uma ferramenta de manutenção do ensino superior, sobretudo, desenvolvendo o crescimento da pós-graduação a partir do ingresso de seus petianos egressos (MELO FILHO, 2019).

Apesar das lutas vencidas o PET só foi efetivamente institucionalizado e assumiu suas características e filosofias atuais em 2005, como apontado por Melo Filho:

\begin{abstract}
A primeira grande modificação foi conceitual e filosófica, pela mudança de nome que passou a ser denominado de Programa de Educação Tutorial, tornando-se a tão almejada política pública de educação com proposição do então presidente Luiz Inácio Lula da Silva e aprovação no Congresso Nacional, da Lei 11.180/2005, que entre outras providências instituiu o Programa de Educação Tutorial. A lei 11.180/2005 foi regulamentada pela Portaria 3.385/2005 (- 2019, p. 48).
\end{abstract}

A regulamentação pela Lei marcou o período em questão, entre 2005 a 2010, intensificou o fortalecimento do programa e a rápida expansão da criação de novos grupos. Entre 2005 e 2010 foram criados 427 grupos nos editais 03/2006; 04/2007; 05/2008 e 05/2009. Junto também a atualização do Manual de Orientações Básicas de 2006 (MELO FILHO, 2019).

O programa viveu a reestruturações de suas concepções por meio da incorporação do Programa Conexões de Saberes, projeto que visava políticas públicas de inclusão. Além da regulamentação legal de funcionamento das Portarias 976/2010 e 343/2013 - importantes instrumentos para o funcionamento do programa (MELO FILHO, 2019).

\title{
O POTENCIAL DE ALCANCE DA LUTA PETIANA
}

O último edital de criação de novos grupos PETs, foi em 2012. Desta forma, hoje (2021), somam-se 842 grupos, em 121 Instituições de Ensino Superior, com cerca de 10.946 estudantes. A estimativa de membros foi feita considerando que cada grupo possua a quantidade máxima de 12 membros bolsistas e um tutor como docente responsável. A média objetiva 
equilibrar o fato de que alguns grupos funcionam com a capacidade mínima, de 6 bolsistas, enquanto outros grupos agregam voluntários para além dos 12 bolsistas.

É claro que a tríade pesquisa, ensino e extensão, orienta as atividades do PETs, todavia, o planejamento de atividades e a organização pauta-se em determinações atualizadas presentes nas Portarias 976/2010 e $343 / 2013$.

A portaria 343/2013, promulgada para atualizar a 976/2010, apresenta características mais voltadas ao funcionamento burocrático do programa, como a fonte e as utilizações dos recursos financeiros; o processo avaliativo; a consolidação do CLAAs (Comitês Locais de Acompanhamento e Avaliação); a relação entre a IES e a SESu etc.

Já a portaria 976/2010, que surgiu como um complemento do MOB - última versão de 2006 - e é um documento que institui determinações sobre a construção dos planejamentos do grupo, além de ser fiel as concepções do programa, como explícito no Art. 20:

Art. $2^{\circ} \mathrm{O}$ PET constitui-se em programa de educação tutorial desenvolvido em grupos organizados a partir de cursos de graduação das instituições de ensino superior do País, orientados pelo princípio da indissociabilidade entre ensino, pesquisa e extensão, que tem por objetivos:

I - desenvolver atividades acadêmicas em padrões de qualidade de excelência, mediante grupos de aprendizagem tutorial de natureza coletiva e interdisciplinar;

II - contribuir para a elevação da qualidade da formação acadêmica dos alunos de graduação;

III - estimular a formação de profissionais e docentes de elevada qualificação técnica, científica, tecnológica e acadêmica;

IV - formular novas estratégias de desenvolvimento e modernização do ensino superior no país;

V - estimular o espírito crítico, bem como a atuação profissional pautada pela cidadania e pela função social da educação superior;

VI - introduzir novas práticas pedagógicas na graduação; (Incluído pela Portaria MEC no 343, de 24 de abril de 2013)

VII - contribuir para a consolidação e difusão da educação tutorial como prática de formação na graduação; e (Incluído pela Portaria MEC no 343, de 24 de abril de 2013)

VIII - contribuir com a política de diversidade na instituição de ensino superior - IES, por meio de ações afirmativas em defesa da equidade socioeconômica, étnico-racial e de gênero. (Incluído pela Portaria MEC no 343, de 24 de abril de 2013).

Revista Eletrônica do Programa de Educação Tutorial - Três Lagoas/MS -

v. 3, n. 3, Outubro (2021).

ISSN 2675 - 1003 
A portaria 976/2010 reforça a importância de que as atividades de pesquisa, ensino e extensão ocorram pautada em fundamentos importantes para o desenvolvimento da educação e da formação cidadã, sobretudo, quanto institui a responsabilidade de que os grupos contribuam com as políticas de diversidades nas IES, com ações afirmativas em defesa da equidade econômica, étnico-racial e de gênero.

A consolidação desses parâmetros representa, em nível escalar, um avanço para a educação brasileira. Pensemos neste momento nos números alcançados a partir do programa. De início, se considerarmos que existem 10.946 estudantes, em diferentes partes do Brasil, presentes em cada região (Norte, Nordeste, Centro-Oeste, Sul e Sudeste), pautando atividades em políticas de diversidade, pode-se, então, considerar o programa como um instrumento potente de transformação social.

Além da transformação social dos membros petianos (10.946), vale ressaltarmos que o PET não limita suas atividades somente aos estudantes do grupo. Dentre os princípios do programa está a extensão, que objetiva a realização de ações externas ao grupo e, por vezes, externas a comunidade acadêmica. Desta forma, não se pode medir, de forma numérica, a potencialidade de transformação social do programa.

O PET possui ainda outras singularidades, como o caso dos PETs Conexões dos Saberes, diferente dos PETs tradicionais, consideram em seus processos seletivos de ingresso as condições socioeconômicas dos estudantes, evidenciando o caráter de manutenção de centenas de estudantes na continuidade do ensino superior.

A bolsa do PET, de $\mathrm{R} \$ 400,00$ (quatrocentos reais), não serve para suprir as demandas acadêmicas dos estudantes, tais como a participação em eventos, compra de livros, compra de materiais de estudos etc. A bolsa, na verdade e na maioria dos casos, serve como fonte de renda para manter os estudantes na universidade pública. Os petianos a utilizam para pagar aluguel, contas básicas, como energia, água, internet e, principalmente, para a alimentação.

Desta forma, não se pode analisar o programa somente pelo viés 
acadêmico, precisa-se de mais atenção para considerar sua dimensão de importância na educação pública brasileira. As pesquisas realizadas para o fechamento do programa, no governo FHC, evidenciaram o potencial produtivo do programa, a excelência dos estudantes que o compõe e o crescimento individual dos egressos que se formam(MELO FILHO, 2019).

É verdade que o PET soma inúmeras características e potenciais, mas, destacaremos uma fundamental para a manutenção da cultura essencialmente brasileira. Trata-se, portanto, de enaltecer a existência dos grupos PETs comunidades tradicionais, que servem como forma de resistência e legitimação às comunidades indígenas e quilombolas. Os grupos PETs comunidades tradicionais evidenciam a originalidade do programa, pautado na resistência e em uma educação plural, que considere diferentes culturas e (re)existências.

Sobre os PETs comunidades tradicionais ainda existem alguns problemas a serem solucionados, sobretudo, no que diz respeito à necessidade da criação de uma Portaria que considere e regulamente os aspectos culturais das comunidades que os compõem. A portaria serviria como forma de proteção dos estudantes que mantêm sua cultura pautada em suas heranças ancestrais.

Por fim, é importante compreender a importância social e o potencial político de luta do Programa de Educação Tutorial. A tríade pesquisa, ensino e extensão, quando realizada com excelência, possibilita formação global para além dos muros das universidades. As portarias que regulamentam o funcionamento dos grupos expressam a importância de o PET exercer sua função ímpar de multiplicação, principalmente, quando as discussões consideram a diversidade e a capacidade de leitura de mundo.

\section{MOBILIZA PET COMO TRINCHEIRA DE LUTA: HISTÓRICO E REIVINDICAÇÕES}

As tantas assertivas do programa e o princípio da formação global, disposto no MOB, possibilita que os estudantes, junto ao trabalho coletivo, desenvolvam também características particulares, como a constituição de autonomia, criatividade, cooperação e senso crítico (ALMEIDA, 2017). Assim: 
Neste objetivo, entende-se por formação ampla dar atenção consciente e voluntária não só a formação técnica, onde o estudante deve se apropriar dos conhecimentos teóricos e metodológicos de sua área, mas também à constituição dos compromissos epistemológicos, éticos, socioambientais e étnicos-raciais necessários para a formação de indivíduo cônscio das questões que perpassam sua atuação científica, profissional e social junto à coletividade onde ele se insere. Espera-se também a construção da autonomia do petiano, ou seja, que este desenvolva a consciência e o controle sobre seu próprio processo de formação (AYALA FILHO, 2019, p. 16-17).

Foi a consolidação dessas características, o histórico de luta e os constantes avanços neoliberais sobre a educação brasileira que contribuíram para a criação de uma frente de luta dos petianos, denominado de Mobiliza PET.

O Mobiliza PET surgiu aliado à Comissão Executiva Nacional do PET (CENAPET ), que é a entidade responsável por representar os petianos discentes e tutores em instâncias superiores e deliberativas, tal como o diálogo com o Ministério da Educação. Desta forma, o Mobiliza PET representa uma Comissão da CENAPET, ele é composto por representantes de todas as regiões do Brasil, eleitos no Encontro Nacional de Grupos PETs (ENAPET), realizado anualmente.

O Mobiliza PET é, de fato, uma trincheira de luta dos petianos e atua como movimento de articulação para as reivindicações do programa, sobretudo, na resistência aos constantes e cada vez mais agressivas investidas na destruição e desmonte da educação pública.

O Mobiliza PET foi criado em 2013, na Universidade de Brasília (UnB), com as seguintes reivindicações: valorização da educação tutorial na graduação; repasse da verba do custeio em tempo hábil; respostas das avaliações de 2010 a 2012; divulgação do programa; estabilidade no Sistema de Gestão do Programa de Educação Tutorial (SIGPET); atualização do MOB. Os problemas pautados no debate de 2013 limitavam-se à realidade e organicidade do PET.

A partir de seu primeiro evento em 2013, o MOBILIZA PET se firmou como a entidade representante do programa de educação tutorial diante às adversidades enfrentadas, tornando-se sua frente de Mobilização em prol da manutenção do programa. (MOBILIZA PET, 2020, p. 9). 
O segundo momento do Mobiliza PET foi em 2015, em Belém/PA, durante o XX ENAPET. Os estudantes buscaram visibilidade para suas lutas por meio de uma passeata pela praça da cidade, cujas reivindicações serviram como críticas aos constantes atrasos das bolsas; a rotatividade compulsória de tutores; a resolução do FNDE que determinava a suspensão de bolsas a qualquer momento.

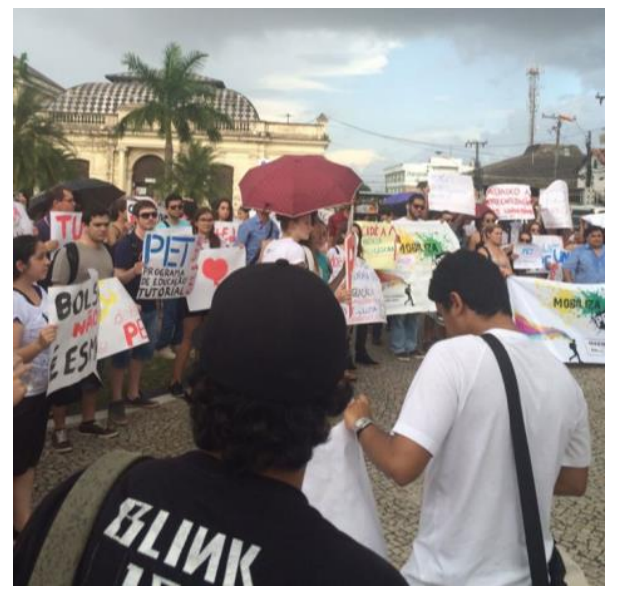

Figura 01 - Mobilização dos estudantes em BELÉM/PA Fonte: Acervo MOBILIZA PET

O terceiro ato do Mobiliza PET ocorreu em Brasília, em 2015, com a participação dos estudantes em uma Audiência Pública e visita nos gabinetes de deputados e senadores, cuja reivindicação consistia na busca pela ampliação e fortalecimento do PET. O momento foi marcado pelas falas de petianos discentes na Comissão de Educação.

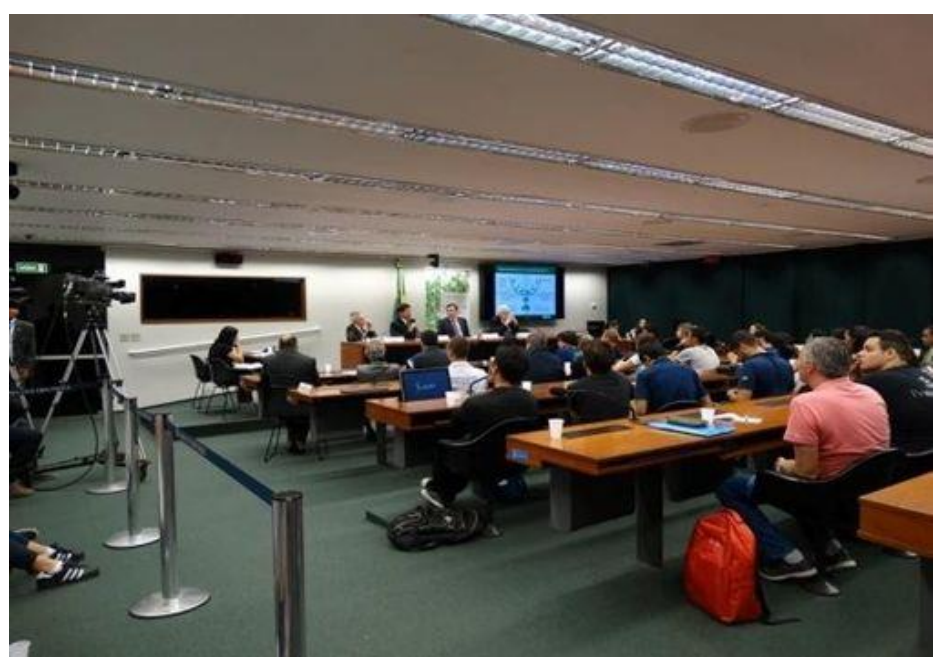

Figura 02 - Audiência pública em Brasília/DF 
Fonte: Acervo MOBILIZA PET

O quarto momento do Mobiliza PET demarcou a utilização da internet e das redes sociais como forma de homogeneizar a luta petiana, uma vez que em novembro de 2016 foi lançada uma semana de Mobiliza PET, a ser realizada em vários lugares do Brasil pelos grupos PETs. As pautas eram a divulgação do programa nas IES; a publicação de um novo MOB; a garantia na regularidade das verbas; um sistema de avaliação para os tutores e a composição paritária do CLAA, entre membros da IES e petianos.

O quinto momento do Mobiliza PET foi um importante marco em sua história e, talvez, o momento fundamental para a sua consolidação. Em 2017, em Brasília, mais de 500 petianos reuniram-se em frente ao MEC para pautar suas reivindicações por meio de gritos de ordem. A frase que marcou este momento foi o grito de resistência "O PET resiste, por isso ele existe". Os petianos fizeram ainda uma longa caminhada com cartazes e um gigantesco abraço ao MEC.

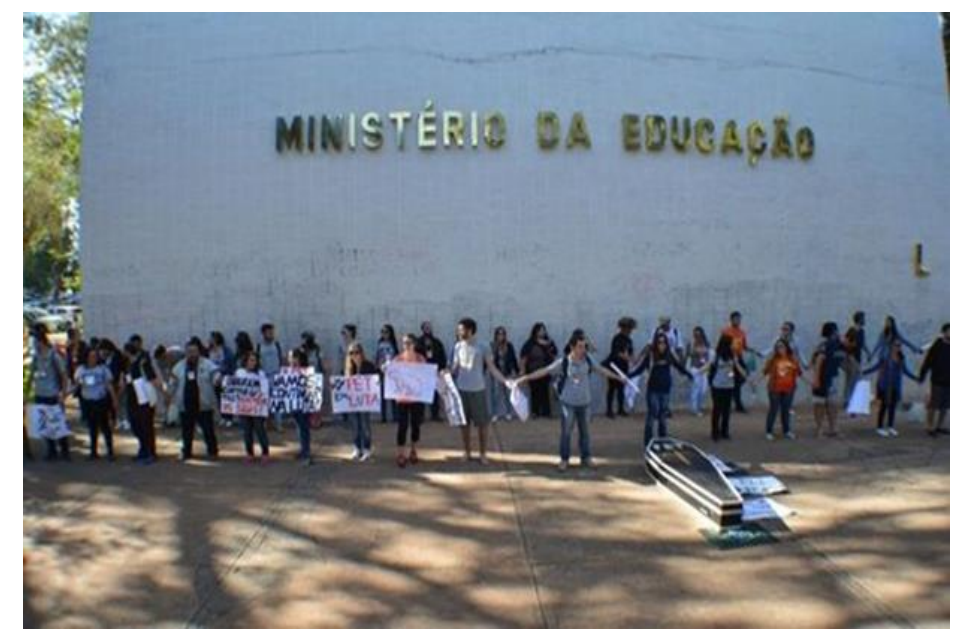

Figura 03 - O abraço petiano ao MEC Fonte: Acervo MOBILIZA PET

O sexto Mobiliza PET ocorreu em Campinas/SP, em 2018, no XXIII ENAPET. O momento em questão instituiu uma Comissão Nacional, com representantes de todas as regiões e articulou grupos de Comitês Locais de Mobilização, por estado e por IES. Neste período o Mobiliza PET passou a pautar debates para além dos problemas da comunidade petiana, destinando 
seus esforços também para lutas mais amplas, como a defesa da educação pública e a resistência aos retrocessos.

O sétimo Mobiliza PET aconteceu em Natal/RN, em 2019, durante o XXIV ENAPET. O momento Mobiliza deste ano foi diferente, houve a organização de uma mesa como todos os representantes de cada região para que pudessem relatar a forma de organização da gestão e realizar reflexões sobre os cortes de $30 \%{ }^{2}$ nas universidades públicas anunciado pelo governo Bolsonaro.

O momento da fala foi marcado por diversas intervenções de petianos que participavam do Mobiliza PET e externalizaram suas indignações, dentre as falas, uma chamou bastante atenção. Houve uma intervenção que relatou um acontecimento daquela tarde, com a notícia do corte de energia na Universidade Federal de Mato Grosso (UFMT ) ${ }^{3}$. A energia foi cortada por falta de pagamento das contas, algo que serviu como materialização dos efeitos dos cortes de verbas como desmonte da educação pública nas universidades brasileiras.

\footnotetext{
${ }^{2}$ Corte de $30 \%$ de verba valerá para todas as universidades federais, diz MEC. Disponível em: $<$ https://educacao.uol.com.br/noticias/2019/04/30/mec-anuncia-corte-de-30-da-verbapara-todas-asfederais.htm\# : : text=Corte $\% 20$ de $\% 2030 \% 25 \% 20$ da $\% 20$ verba, $\% 2$ F04\%2F2019\%20\%2D $\% 20$ UL $\% 20$ Educa $\%$ C3\%A7\%C3\%A30>.

3 UFMT tem energia cortada por falta de pagamento. Disponível em: < https://agenciabrasil.ebc.com.br/educacao/noticia/2019-07/ufmt-tem-energia-cortada-porfalta-de-pagamento>.
} 


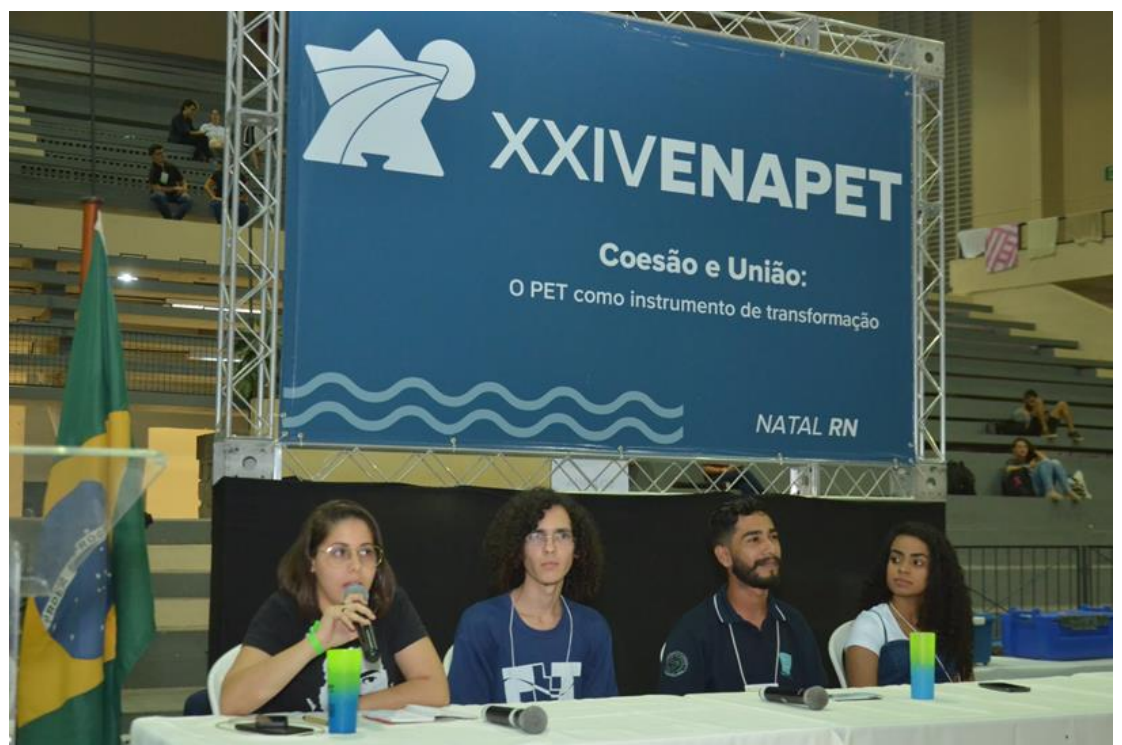

Figura 04 - Mobiliza PET - Natal/RN

Fonte: Acervo Mobiliza PET

Ainda em 2019 houve a realização de outro Mobiliza PET, desta vez, com atividades em diversos locais do país, com objetivo de fomentar a mobilização petiana; divulgação do programa e somar parcerias com outras entidades de luta. Além da promoção de discussões sobre o Mobiliza e sua importância para a manutenção do PET.

Em 2020, já no contexto de pandemia, foi realizado também um momento de Mobiliza PET, que ocorreu de forma virtual, por meio de lives e atos de Mobilização. A potencialidade alcance das atividades digitais proporcionou proximidade da comissão nacional do Mobiliza com a comunidade petiana.

Assim como a luta petiana, o Mobiliza PET passou por diferentes momentos de construção até se consolidar como uma importante trincheira de luta. No presente momento o Mobiliza PET alcançou grande participação de petianos e a comissão nacional passou a se articular e realizar comunicação com a comunidade petiana por meio de suas redes sociais, principalmente, com uso do Instagram.

O Mobiliza PET, enquanto movimento representativo da comunidade petiana, pauta questões importantes acerca da manutenção do programa. Dentre os debates levantados, a cobrança pela criação de editais 
para novos grupos faz parte da busca pelo fortalecimento e expansão do programa.

As constantes reivindicações para que haja liberação do custeio em tempo hábil servem como forma de crítica a maneira em que o MEC lida com as demandas financeiras do programa. O custeio faz parte de uma verba anual que os grupos PETs recebem para compra de materiais que subsidiem a realização das atividades previstas no planejamento. O valor total corresponde a soma de $\mathrm{R} \$ 400,00$ por estudante.

O Mobiliza pauta também o debate referente a atualização e/ou criação de um novo MOB - documento base sobre o programa - considerando que a última atualização do Manual de Orientações Básicas foi em 2006, desta forma, o documento encontra-se obsoleto em determinadas questões, sobretudo porque não contempla as particularidades do PETs Conexões dos Saberes.

Além das reivindicações em nível de estruturação do programa, uma pauta constante do debate petiano é a luta contra o atraso das bolsas. Os petianos bolsistas utilizam a bolsa, na maioria das vezes, para subsidiar sua permanência na universidade, no entanto, essa realidade não é levada em consideração durante o período de pagamento, o que representa um descaso com a comunidade e suas demandas pessoais. Apesar das múltiplas reinvindicações contra o atraso nas bolsas, o problema ainda se mantém presente na realidade petiana, conforme relatado em notícia:

Durante a pandemia do Covid-19, o valor destinado aos bolsistas $(R \$ 400,00)$ tem sido ainda mais importante para suprir necessidades básicas, como alimentação e moradia. A petiana Ana Lúcia Ormond, do PET Floresta da Rural, diz ter sido afetada pelo atraso do pagamento da assistência estudantil: "Assim como a demora para fazer as compras do mês, fiquei com contas atrasadas." A discente também expôs o receio da recorrência do atraso das bolsas: "Dependo da bolsa para a minha manutenção e é minha fonte de renda. Eu pago minhas despesas e ajudo financeiramente minha mãe com o que recebo.", completou a petiana (GRUPOS PET RURAL UFRRJ, 2020).

Embora o Mobiliza persista em determinadas frentes de luta que se referem mais a organização do PET, o movimento passou também a agregar 
debates mais amplos, principalmente os que estão relacionados a defesa da educação pública, gratuita, laica e de qualidade e os debates sobre a diversidade.

Portanto, cabe ressaltarmos que o Mobiliza PET é uma importante trincheira representativa da luta petiana, especialmente, porque homogeneiza reivindicações em âmbito nacional e possibilita que diversos grupos, por todo o Brasil, participem da mobilização em defesa da educação.

\section{CONSIDERAÇÕES FINAIS}

O objetivo deste trabalho consistiu em realizar uma análise do potencial de alcance da luta petiana, pautada em sua jornada histórica e a partir da concepção de que o Mobiliza PET é uma trincheira estratégica para a consolidação da luta petiana.

As considerações sobre o histórico do programa e os diversos desafios enfrentados, em diferentes contextos políticos, até sua consolidação evidenciam a constante trajetória, marcada por ações coletivas, na luta em defesa e pela manutenção do PET.

Compreende-se, então, que o PET possui ímpar capacidade de alcance e alto potencial de transformação social nos debates em que pauta, sobretudo, pelo fato de que é instituído ao programa a realização de atividades de ensino, pesquisa e extensão, incluído à elas a importância de agregar pautas de diversidade de gênero, questão socioeconômica e étnicoracial. Desta forma, apesar da singularidade regional dos grupos, a formação cidadã torna-se parte da responsabilidade petiana.

Por fim, apesar de estarmos nos referindo de um programa de 42 anos, criado inicialmente para um grupo seleto de alunos, denominado de Programa Especial de Treinamento, cujo objetivo era alimentar o ingresso na pós-graduação, o PET de hoje - Programa de Educação Tutorial - rompeu com o viés tradicionalista, pautado em dados de excelência. O programa consolidou a capacidade de realizar a formação global, junto a tríade da pesquisa, ensino e extensão, baseando suas ações em pautas de diversidade, agregando todas e todos que o desejarem compor, rompendo com a exclusão social e potencializando a transformação social baseada na educação. 


\section{REFERÊNCIAS}

AYALA FILHO, Alvaro Leonardi. A EDUCAÇÃO TUTORIAL NA PERSPECTIVA DA TEORIA HISTÓRICO CULTURAL DA ATIVIDADE. Revista Eletrônica do Programa de Educação Tutorial-Três Lagoas/MS, v. 1, n. 1, p. 10-32, 2019.

BRASILIA. PORTARIA No - 343, de 24 DE ABRIL DE 2013. Altera dispositivos da Portaria MEC no 976, de 27 de julho de 2010, que dispõe sobre o Programa de Educação Tutorial - P E T. Disponível em:

<http://sigpet.mec.gov.br/docs/Portaria_343_2013.pdf> Acesso em: 27, abril, 2021.

BRASILIA. PORTARIA No 976, DE 27 DE JULHO DE 2010(*) O MINISTRO DE ESTADO DA EDUCAÇÃO, no uso de suas atribuições legais, tendo em vista o disposto na Lei no 11.180, de 23 de setembro de 2005, resolve: Disponível em:

<http://sigpet.mec.gov.br/docs/Portaria_976_2010.pdf> Acesso em: 27, abril, 2021.

DE ALMEIDA, Rosemeire A. PET-GEOGRAFIA/UFMS (1988-2017):

HISTÓRICO, PROPÓSITOS E REALIZAÇÕES. Revista Eletrônica da Associação dos Geógrafos Brasileiros Seção Três Lagoas, p. 243-253, 2017.

GRUPOS PET RURAL UFRRJ. Atraso de bolsas afeta a vida de petianos em todo o Brasil. Disponível em <https://r1.ufrrj.br/grupospetrural/atraso-de-bolsas-afeta-a-vida-depetianos-em-todo-o-brasil/> Acesso 27 de abril de 2021.

MELO FILHO, José Fernandes. Programa De Educação Tutorial: trajetória, desafios e articulações. Revista Eletrônica do Programa de Educação Tutorial-Três Lagoas/MS, v. 1, n. 1, p. 33-56, 2019.

Programa de Educação Tutorial. Mobiliza PET: o PET resiste, por isso ele existe. Disponível em <https://drive.google.com/file/d/1APG9QggXV1aS35bYg8UerANee_50shin/ view> Acesso em 27 de abril de 2021.

Recebido em: 01 de Maio de 2021. Publicado em: 31 de Outubro de 2021. 